\title{
Increased Expression of Type-I Collagen in Malignant Colorectal Lesion and Positive Correlations with Clinical Factors*
}

\section{Expressão aumentada do colágeno tipo I na lesão colorretal maligna e correlações positivas com fatores clínicos}

\author{
Monique Pinheiro Santos ${ }^{1} \quad$ Izabela Silva Sinara Alves $^{1}$ Willian Grassi Bautz ${ }^{2}$ \\ Flavya da Silva Souza Ribeiro ${ }^{3}$ Luciano Pinto Nogueira da Gama ${ }^{4}$ Raquel Spinassé Dettogni ${ }^{2}$ \\ Letícia Nogueira da Gama-de-Souza2
}

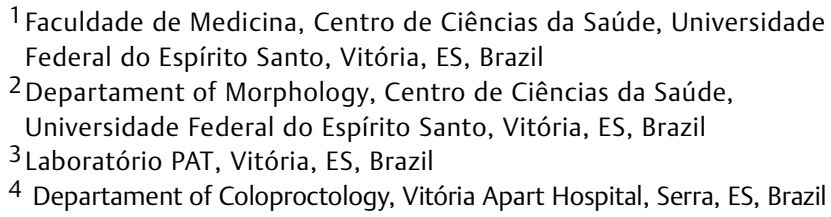

Address for correspondence Letícia Nogueira da Gama-de-Souza, Ph. D, Av. Marechal Campos, 1468. Maruípe, Vitória, ES, 29043-910, Brazil (e-mail: leticia.souza@ufes.br).

J Coloproctol 2021;41(1):63-69.

\begin{abstract}
Keywords

- colorectal cancer

- colorectal adenoma

- type-I collagen

- extracellular matrix

Objective Type-I collagen (Col-I) is one of the main macromolecules of the extracellular matrix, and it is involved in the desmoplastic stromal reaction, an indicator of worse prognosis in cases of colorectal cancer (CRC). The purpose of the present study was to investigate Col-I expression in cases of CRC and adenoma and to correlate with the clinical data and the data regarding the lifestyle of the patients.

Methods A retrospective study including 22 patients with adenoma and 15 with CRC treated at a coloproctology service. The clinical and lifestyle data were obtained through medical records, and Col-I expression was investigated by immunohistochemistry.

Results Women represented most cases of adenoma (63.64\%), whereas CRC was found mainly in men $(73.33 \%)(p=0.0448)$. Immunoexpression of Col-I showed a basement membrane thickening in areas of lining of epithelium and around the glands in both lesions. The cases of CRC had a quite evident fibrosis process in the stroma. The quantitative analysis demonstrated a higher protein expression in CRCs compared to adenomas $(p=0.0109)$, as well as in female patients $(p=0.0214)$, patients aged $\geq$ 50 years $(p=0.0400)$, and in those with a positive family history of colorectal disease $(p=0.0292)$. These results suggested a remodeling of the microenvironment of the
\end{abstract}

Worked developed at the Department of Morphology, Centro de Ciências da Saúde, Universidade Federal do Espírito Santo, ES, Brazil. received

August 9, 2020

accepted

August 30, 2020
DOI https://doi.org/

10.1055/s-0040-1722562.

ISSN 2237-9363. (c) 2021. Sociedade Brasileira de Coloproctologia. All rights reserved.

This is an open access article published by Thieme under the terms of the Creative Commons Attribution-NonDerivative-NonCommercial-License, permitting copying and reproduction so long as the original work is given appropriate credit. Contents may not be used for commercial purposes, or adapted, remixed, transformed or built upon. (https://creativecommons.org/ licenses/by-nc-nd/4.0/)

Thieme Revinter Publicações Ltda., Rua do Matoso 170, Rio de Janeiro, RJ, CEP 20270-135, Brazil 


\section{Resumo}

\section{Palavras-chave \\ - câncer colorretal \\ - adenoma colorretal \\ - colágeno tipo I \\ - matriz extracelular}

tumor in CRC carcinogenesis. Importantly, the clinicopathologic positive correlations showed a plausible link between the patient's profile and the immunohistochemical findings, which indicate a possible form of patient stratification.

Conclusion The immunohistochemical analysis encourages the performance of more comprehensive studies to ascertain if our results could be a tool for the diagnosis and monitoring of the patients.

Objetivo O colágeno tipo I (Col-I) é uma das principais macromoléculas da matriz extracelular, e está envolvido na reação desmoplástica estromal, um indicador de pior prognóstico em casos de câncer colorretal (CCR). O objetivo foi investigar a expressão do Col-I em casos de CCR e adenoma, e correlacioná-la com dados clínicos e de estilo de vida dos pacientes.

Metodologia Foi realizado um estudo retrospectivo com 22 pacientes com adenoma e 15 com CCR tratados em um serviço de coloproctologia. Os dados dos pacientes foram obtidos dos prontuários médicos, e a expressão do Col-I foi investigada por imunohistoquímica.

Resultados As mulheres representaram a maioria dos casos de adenomas $(63,64 \%)$, enquanto o CCR $(73,33 \%)(p=0,0448)$ foi mais comum entre os homens. A imunoexpressão de Col-I mostrou espessamento da membrana basal em áreas de revestimento do epitélio e em volta de glândulas em ambas as lesões. O CCR apresentou fibrose no estroma. As análises quantitativas demonstraram maior expressão proteica no CCR $(p=0,0109)$, assim como em mulheres $(p=0,0214)$, pacientes com idade $\geq 50$ anos $(p=0,0400)$, e em pacientes com histórico positivo de doença colorretal na família $(p=0,0292)$. Estes resultados sugerem a remodelação do microambiente tumoral na carcinogênese do CCR. As correlações clínico-patológicas positivas mostram uma ligação plausível entre o perfil do paciente e os achados imunohistoquímcos, o que indica uma possível forma de estratificação dos pacientes.

Conclusão As análises imunohistoquímicas estimulam a execução de estudos mais abrangentes para confirmar se nossos resultados poderão ser uma ferramenta para o diagnóstico e o monitoramento dos pacientes.

\section{Introduction}

Colorectal cancer (CRC) is the third most common cancer and the third cancer-related cause of death worldwide. ${ }^{1}$ Although survival rates have improved in recent years, approximately $30 \%$ of CRC patients still develop local recurrence, probably resulting from micro-metastatic dissemination or distant metastases. ${ }^{2}$ This aspect is related to the behavior of the disease, which usually does not present symptomatology in the initial stages. Factors such as age and family history, as well as genetic and environmental factors, have a positive correlation with CRC. ${ }^{3-5}$

Most lesions follow a specific sequence of mutations, the "adenoma-carcinoma sequence": ${ }^{4}$ initially, the normal epithelium is transformed into a hyperproliferative tissue; later, it loses organization and structure and acquires the capacity to form adenomatous polyps, which can evolve to CRC. ${ }^{3}$

The microenvironment of the tumor has demonstrated an important regulatory role in CRC pathogenesis. ${ }^{6-8}$ During the progression of the disease, excessive remodeling of the extracellular matrix (ECM) is characterized by increased collagen deposition (desmoplasia) and by its crosslinking, which promotes tissue stiffening. ${ }^{7,9}$ Yue et al. ${ }^{10}$ have shown that cancerous stroma interactions are highly dependent on matrix stiffness, interfering in processes such as the migration of cancerous cells. ${ }^{10}$

The desmoplastic stromal reaction is rich in type-I collagen (Col-I) and is considered an indicator of worse prognosis in primary CRC. ${ }^{9,11}$ The progressive increase in Col-I expression occurs due to abnormal recruitment of fibroblasts and myofibroblasts, a phenomenon associated with tumor-cell proliferation, angiogenesis and metastasis. ${ }^{12,13}$ Type-I collagen is highly expressed in infiltrative growth tumors. ${ }^{14}$ Its production during the remodeling of the ECM in carcinogenesis results in a precarcinogenic niche, which works as a tumor escape. ${ }^{12}$ Furthermore, the high expression of Col-I in the stroma is related to the ability of CRC cells to exhibit increased proliferation, chemoresistance, and survival. ${ }^{8,9}$ This fact contributes to the increased invasiveness and manifestation of a malignant phenotype in the colorectal region, reducing cell adhesion and differentiation as an early event in tumorigenesis. ${ }^{15}$

Therefore, the study of Col-I expression by immunohistochemistry in benign and malignant human samples from 
the colorectal region is important to clarify the local alterations that occur in the ECM throughout the progression of carcinogenesis. Moreover, the association between clinical and histopathological features may help select the best actions in the medical monitoring routine.

\section{Methods}

\section{Sample Selection}

The present is a retrospective study, and the patients were selected from the Coloproctology Service at Vitória Apart Hospital, in the state of Espírito Santo, Brazil, between 2015 and 2017. All patients underwent a colonoscopy procedure, and no change in the care protocol was performed for the present study. The samples were obtained from excisional and incisional biopsies of colonic lesions with a suspicion of adenoma or CRC. Slides were prepared and assigned by the Pathological Anatomy (PAT) Laboratory, which is linked to the Coloproctology Service. The clinical profile was obtained from the medical records, and it included: gender, age, family history of benign or malignant colorectal diseases, smoking, and alcohol consumption. The following inclusion criteria were adopted: completion of the questionnaire on clinical profile, availability of data regarding the lesion (histopathological diagnosis), and sufficient tissue for analysis. The present research was approved by the Ethics in Research Committee of Vitória Apart Hospital (under process number 406.002). All patients agreed to participate and signed the consent form.

\section{Immunohistochemistry}

Rabbit polyclonal anti-Col I antibody (Ab34710) (Abcam, Cambridge, MA, US) diluted 1:400 in phosphate-buffered saline (PBS) was used for the detection of Col-I. After deparaffinization and rehydration, the slices were pretreated with citrate buffer ( $\mathrm{pH}$ : 6.0 ) for antigen retrieval. Then, the sections were treated with a protein block solution (DPB125, Spring Bioscience Corp., Pleasanton, CA, US) for 10 minutes at room temperature and incubated with the respective primary antibody in a humidified chamber overnight at $4^{\circ} \mathrm{C}$. Endogenous peroxidases were blocked with hydrogen peroxide block (DHP-125, Spring Bioscience Corp.) for 10 minutes. Immunodetection was performed with a biotin-free immunoenzymatic antigen detection system (Reveal System, SPB-999, Biogen, São Paulo, SP, Brazil). The sections were briefly incubated with a complement reagent (DCMT-999, Spring Bioscience Corp.) for 10 minutes, and then, with horseradish peroxidase (HRP) conjugate for 15 minutes. Immunoreactivity was visualized using a 3.3'diaminobenzidine (DAB) (DABC-004 and DABS-125, Spring Bioscience Corp.) as the chromogen. Finally, the slides were lightly counterstained with Mayer hematoxylin. After being washed with water and dehydrated in alcohol series, the slides were cleaned with xylene and mounted with dibutylphthalate polystyrene xylene (DPX) (Sigma-Aldrich, St. Louis, MO, US). The slides were washed thoroughly with PBS during the immunohistochemistry process, and negative controls were performed omitting the primary antibody.

\section{Col-I Quantitative Analysis}

The immunostained sections were analyzed and scored blindly for clinical information by a single investigator using a PrimoStar microscope with a Zeiss AxioCam ERC5s digital camera (Carl Zeiss Vision GmbH, Aalen, Germany) and the Axio Vision 4.2 Release 4.8.2 image software (Carl Zeiss Vision $\mathrm{GmbH}$ ). For each slide, two images of the hot spots of the ECM were obtained and imported to the Image J (public domain, available in: https://imagej.nih.gov/ij/download.html) software. Then, the area of interest was defined: area and fraction of the ECM. The following segmentation plugin was applied to the expression analysis: color deconvolution, with the vector HDAB. The bottom coloration, the hematoxylin and the DAB were separated. The settings of the limits for the positive $D A B$ were made with the threshold tool adjust, and the analyses were concluded with the measure tool. For each section, a measurement of the two evaluated areas was defined. Lastly, the data were stored in Microsoft Excel 2016 (Microsoft Corp. Redmond, WA, US) spreadsheets.

\section{Statistical Methods}

The analyses were performed with the Graphpad Prism (GraphPad Software, Inc., San Diego, CA, US) software, version 6.0. The Fisher exact test was applied to evaluate the clinical data. The Mann-Whitney test was applied to analyze Col-I expression. The associations among the clinical data, the lesion and the profile expression were analyzed by the two-way analysis of variance (ANOVA) and the Kruskal-Wallis test. In all tests, values of $p<0.05$ were considered statistically significant.

\section{Results}

The study sample consisted of 22 patients diagnosed with colorectal adenoma histopathology and 15 patients with CRC. Some patients with adenoma $(n=11)$ had multiple lesions, so the total number of surgical specimens was 48 (33 adenomas and 15 CRCs). Regarding the clinical data, we observed that women were the majority in the adenoma group (63.64\%), whereas CRC cases were found mainly in men (73.33\%) and this difference was statistically significant $(p=0.0448)$. Individuals aged $\geq 50$ years represented most cases of adenoma (90.91\%) and CRC (66.67\%). Family history was found in about $40 \%$ of the CRC cases. Finally, smoking was reported by $36.6 \%$ of the patients diagnosed with adenoma and by $26.67 \%$ of the CRC patients, while alcoholism was mentioned by $59.09 \%$ of adenoma cases and by $40 \%$ of CRC patients. - Table 1 shows all clinical data.

Regarding Col-I analysis, we could observe in different areas of the ECM that all samples had some degree of expression, with important variation between the two lesions. The normal aspect of loose connective tissue was visualized only in adenoma lesions (-Fig. 1A). In interface areas between lining epithelium and underlying conjunctiva, it was possible to detect collagen deposition in the basement membrane (-Fig. 1B), which was also observed around the glands (-Fig. 1C). In CRC cases, the fibrosis process in the stroma due to increased Col-I was quite evident (-Fig. 1D). 
Table 1 Clinical data and data on the lifestyle of the patients

\begin{tabular}{|c|c|c|c|c|}
\hline & & Adenoma & $\begin{array}{l}\text { Colorectal } \\
\text { cancer }\end{array}$ & \multirow[t]{2}{*}{$p$-value } \\
\hline & & $\begin{array}{l}\text { Relative } \\
\text { frequency: } \\
n(\%) \\
(n=22)\end{array}$ & $\begin{array}{l}\text { Relative } \\
\text { frequency: } \\
n(\%) \\
(n=15)\end{array}$ & \\
\hline \multirow[t]{2}{*}{ Gender } & Female & $14(63.64)$ & $4(26.67)$ & \multirow[t]{2}{*}{$0.0448^{*}$} \\
\hline & Male & $8(36.36)$ & $11(73.33)$ & \\
\hline \multirow{2}{*}{$\begin{array}{l}\text { Age } \\
\text { (years) }\end{array}$} & $<50$ & $2(9.09)$ & $5(33.33)$ & \multirow[t]{2}{*}{0.0953} \\
\hline & $\geq 50$ & $20(90.91)$ & $10(66.67)$ & \\
\hline \multirow{2}{*}{$\begin{array}{l}\text { Family } \\
\text { history }\end{array}$} & Yes & $9(40.91)$ & $6(40.00)$ & \multirow[t]{2}{*}{1.0000} \\
\hline & No & 13 (59.09) & $9(60.00)$ & \\
\hline \multirow[t]{2}{*}{ Smoking } & Yes & $8(36.36)$ & $4(26.67)$ & \multirow[t]{2}{*}{0.7235} \\
\hline & No & $14(63.64)$ & $11(73.33)$ & \\
\hline \multirow[t]{2}{*}{ Alcoholism } & Yes & 13 (59.09) & $6(40.00)$ & \multirow[t]{2}{*}{0.3245} \\
\hline & No & $9(40.91)$ & $9(60.00)$ & \\
\hline
\end{tabular}

Notes: *Statistically significant; Fisher exact test.

A basement membrane thickening, in the lining (-Fig. 1E) and in the glandular epithelium ( $\mathbf{- F i g . ~ 1 F ) ~ w a s ~ a l s o ~ o b s e r v e d ~}$ in these lesions. In the quantitative analysis of the labeled area fraction, higher Col-I expression was confirmed in CRC cases in relation to adenomas $(p=0.0109)$. - Table 2 presents the means and standard errors of the mean (SEM) of the expression of the Col-I fraction area.

Finally, association analyses between the clinicopathologic data and immunohistochemical findings resulted in positive relationships regarding gender, age, and family history and Col-I expression. Higher protein levels were observed in individuals with a positive family history of adenoma or carcinoma ( - Fig. 2A, $p=0.0325$ ), women diagnosed with CRC ( - Fig. 2B, $p=0.0251$ ), and patients aged $\geq 50$ years ( - Fig. 2C, $p=0.0446$ ). Furthermore, there was a tendency towards higher levels of Col-I labeling among alcohol consumers with adenoma ( $\boldsymbol{F}$ Fig. $\mathbf{2 D}, p=0.0761$ ) and smokers with adenoma or CRC ( - Fig. 2E, $p=0.0572$ ).

\section{Discussion}

In the present study, we analyzed Col-I expression in patients diagnosed with CRC and adenoma, and its correlation with clinical data and data on the lifestyle of the patients. Positive correlations between factors related to the patients and the immunohistochemical findings were observed regarding age, gender, and family history. The levels of Col-I were significantly elevated in the CRC stroma compared with benign lesions.

The onset an development of CRC are induced by a combination of genetic and environmental factors, whose study is essential for the establishment of new prevention strategies. ${ }^{5}$ Although most genes involved in CRC have been well characterized, the influence of additional environmental factors on this disease remains unclear. ${ }^{4}$ When analyzing the patients' clinical profile, we observed a higher frequency of individuals
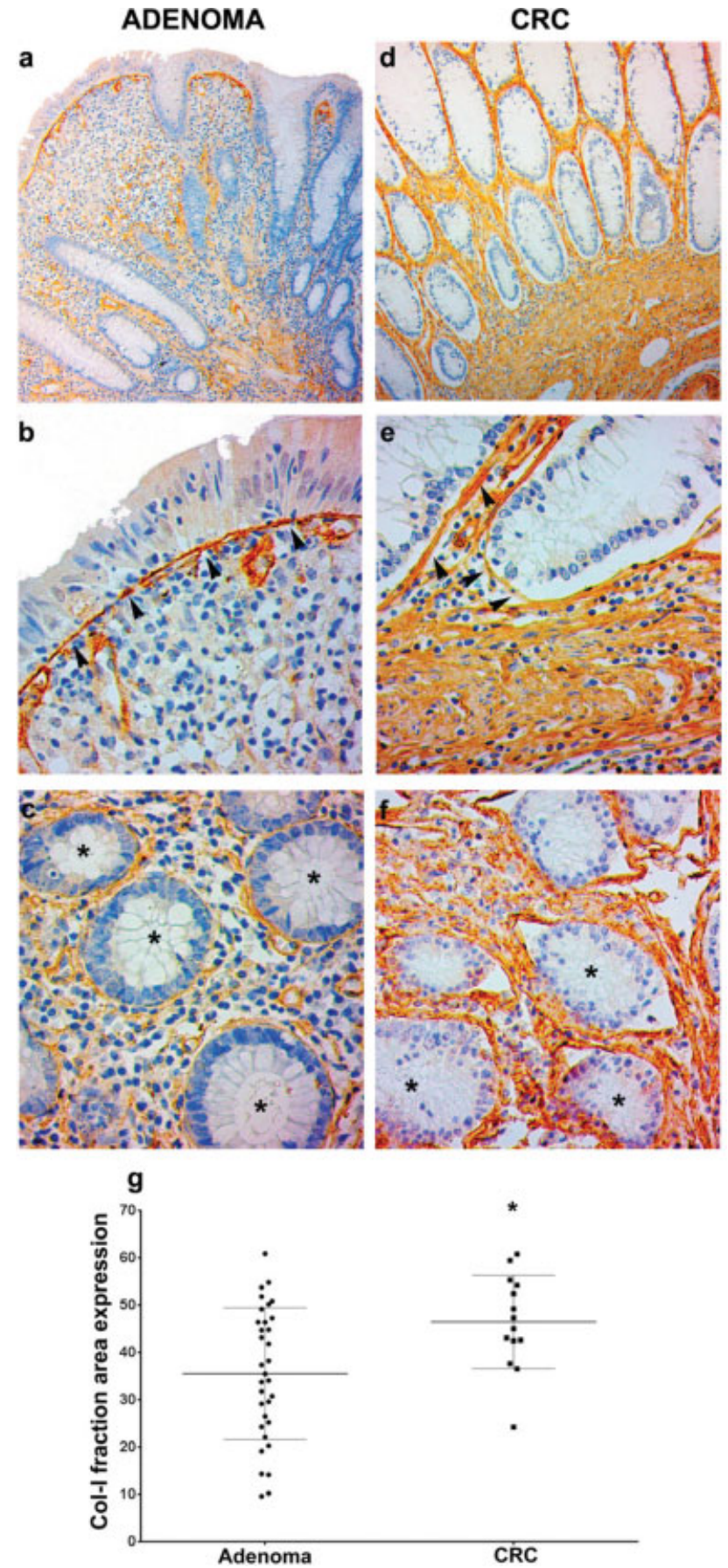

Fig. 1 The immunoexpression of type-I collagen (Col-I) in adenomas and colorectal cancer (CRC) shows increased protein deposition in malignant lesions. The stroma of the adenoma preserving the aspect of loose connective tissue (A). At a higher magnification, it is possible to observe a collagen deposit in the basement membrane at the interface between the lining epithelium and the connective tissue (arrowheads) (B), which was also observed around the glands (the asterisks show the gland lumens) (C). In CRC lesions, stroma fibrosis was observed, with the entire tissue being taken by the Col-I deposit (D). In addition, thickening of the basement membrane occurred in interface areas of the lining epithelium (E) and glandular epithelium (the asterisks show theb gland lumens) (F). Magnifications: A and D: 100X; C, E, and F: 400X; immunohistochemical method.

aged $\geq 50$ years, which is consistent with the literature. ${ }^{4,16}$ Age is one of the main risk factors for CRC, and after the sixth decade of life, the chance of developing CRC is markedly 
Table 2 Mean and standard error of the mean of type-I collagen fraction area in cases of adenoma and colorectal cancer

\begin{tabular}{|l|l|l|l|}
\hline & $\begin{array}{l}\text { Adenoma } \\
(\boldsymbol{n}=33)\end{array}$ & $\begin{array}{l}\text { CRC } \\
(\boldsymbol{n}=14)\end{array}$ & -value \\
\hline Median \pm SEM & $35.50 \pm 2.432$ & $46.21 \pm 2.647$ & $0.0148^{*}$ \\
\hline $\begin{array}{l}\text { 95.24\% } \\
\text { confidence } \\
\text { interval }\end{array}$ & -19.01 to -2.14 & \\
\hline
\end{tabular}

Abbreviations: CRC, colorectal cancer; SEM, standard error of the mean. Note: *Statistically significant; Mann-Whitney test.

increased. ${ }^{4}$ There was a predominance of CRC cases among men, which is also in agreement with a previous study. ${ }^{17}$ Family history of colorectal disease was reported by about $40 \%$ of the patients. It has already been shown that having one or two first-degree relatives with CRC is associated, respectively, with a 2.26- and a 3.76-fold greater risk of developing cancer. ${ }^{3}$ This aspect may be related to inherited mutations or to the environment into which the individual is inserted. ${ }^{4}$

Regarding lifestyle, reports of drinking and smoking were found in cases of adenoma and CRC. Prospective-cohort and case-report studies indicate that high alcohol intake increases the risk of developing CRC, although some of the data have shown to be inconsistent or with only modest associations. ${ }^{18}$ Smoking, in turn, can increase the chances of developing CRC by up to $10.8 \%$. Cigarettes, for example, release metabolites that can easily reach the intestine and cause the formation of polyps. ${ }^{4}$

In the process of carcinogenesis, it was described that tumor cells release factors before and upon arrival at the metastatic niche in order to convert an unfavorable environment of a distant site into favorable surroundings. ${ }^{7,19}$ In this context, the ECM emerged as an active participant in the carcinogenic process. Deregulation of the biochemical and physical characteristics of the ECM, such as composition, architecture, or rigidity, are associated with loss of stem-cell differentiation, epithelial-mesenchymal transformation and abnormal modulation of cell migration, differentiation, and proliferation, thus supporting the onset and progression of the cancer. ${ }^{13,20}$

Previous data demonstrated that Col-I is highly expressed in CRC with an invasion phenotype, ${ }^{15}$ and its expression has been associated with increased tumor-cell proliferation, angiogenesis, and metastasis. ${ }^{12}$ A myofibroblast-mediated desmoplastic stromal reaction rich in fibrillar collagens (types I and III) is said to be an indicator of worse prognosis in primary CRC. ${ }^{12}$ It has also been observed that the ECM deposition, as well as the release of cytokines and growth factors, stimulate angiogenesis and alter the immune function, enabling the occurrence of tumor growth and metastasis. ${ }^{21}$ The analysis of Col-I expression demonstrated increased expression in cases of CRC in comparison to adenomas; still, the stroma of the malignant condition was filled by collagen, involving cancer cells. Moreover, its deposition was not restricted to deep stroma areas; thickening of the basement membrane at the interface of the conjunctivallining epithelium, as well as around the glands, has also been observed. Zou et al. ${ }^{15}$ observed similar findings. Alves et al. ${ }^{16}$ also described thickening of the basement membrane and fibrosis around glands in adenomas, and around vessels in high-grade dysplasia adenomas and CRC. The authors ${ }^{16}$ also mentioned that in dense areas of CRC, a diffuse disorganization of the ECM was observed.

Increasing Col-I expression, even in benign stages, indicates a possible role in tumor onset and progression. ${ }^{12}$ This protein activation may be an early event in carcinogenesis by facilitating tumor invasion. ${ }^{15}$ Kehlet et al. ${ }^{7}$ demonstrated higher serum levels of Col-I-derived fragments in patients with stage-IV tumors compared to all other CRC stages, showing that collagen remodeling is part of the progression of this cancer. Still, a review ${ }^{9}$ of 679 stage-II CRC patients demonstrated that the categorization of the desmoplastic reaction could be a new useful prognostic factor in these patients due to the fact that it outperformed other conventional prognostic factors.

Finally, positive associations found between the clinical data and Col-I immunoreactivity reinforce the multifactorial aspect present in the development of colorectal lesions. Higher levels of Col-I have been found in women with CRC, and in patients aged $\geq 50$ years also diagnosed with cancer. The relationship between family history and higher Col-I expression was found in both adenoma and CRC. These data indicate a possible form of stratification of the patients, which, according to the clinical profile, could be at a higher risk of developing more aggressive behavioral lesions. This strategy clearly depends on future broader and more comprehensive studies. The link between the profile of the patient and the immunohistochemical findings has been discussed in the context of other diseases, such as oral cancer, in which the expression of ECM molecules has been positively related to the gender, age, and smoking habit of the patients. ${ }^{22}$

The search for possible molecules that really represent biomarkers for cancer progression is a relevant field that can impact directly in the prognosis and treatment efficacy. But larger longitudinal studies are needed in order to better comprehend the cellular events that lead to ECM deregulation of biochemical and physical features. However, our preliminary findings suggest that an increase in the Col-I expression and consequent alteration of the tumor microenvironment occur in the pathway progression colorectal carcinogenesis. The knowledge of events that affect the colon, from benign stages to the establishment of cancer, will facilitate the definition of potential biomarkers to be used in the management of CRC patients. In addition, a link between the clinical and pathological findings, as found in the present study, may play an important role in the prognosis of CRC.

The most obvious limitations of the present study are the sample size, in part due to the design of the study and the decision to select patients from a single coloproctology service, and to the use of a single technique. Thus, any statement herein made requires a complementary study, and the findings are only suggestive. On the other hand, the main idea was to compare Col-I deposition on the stroma 

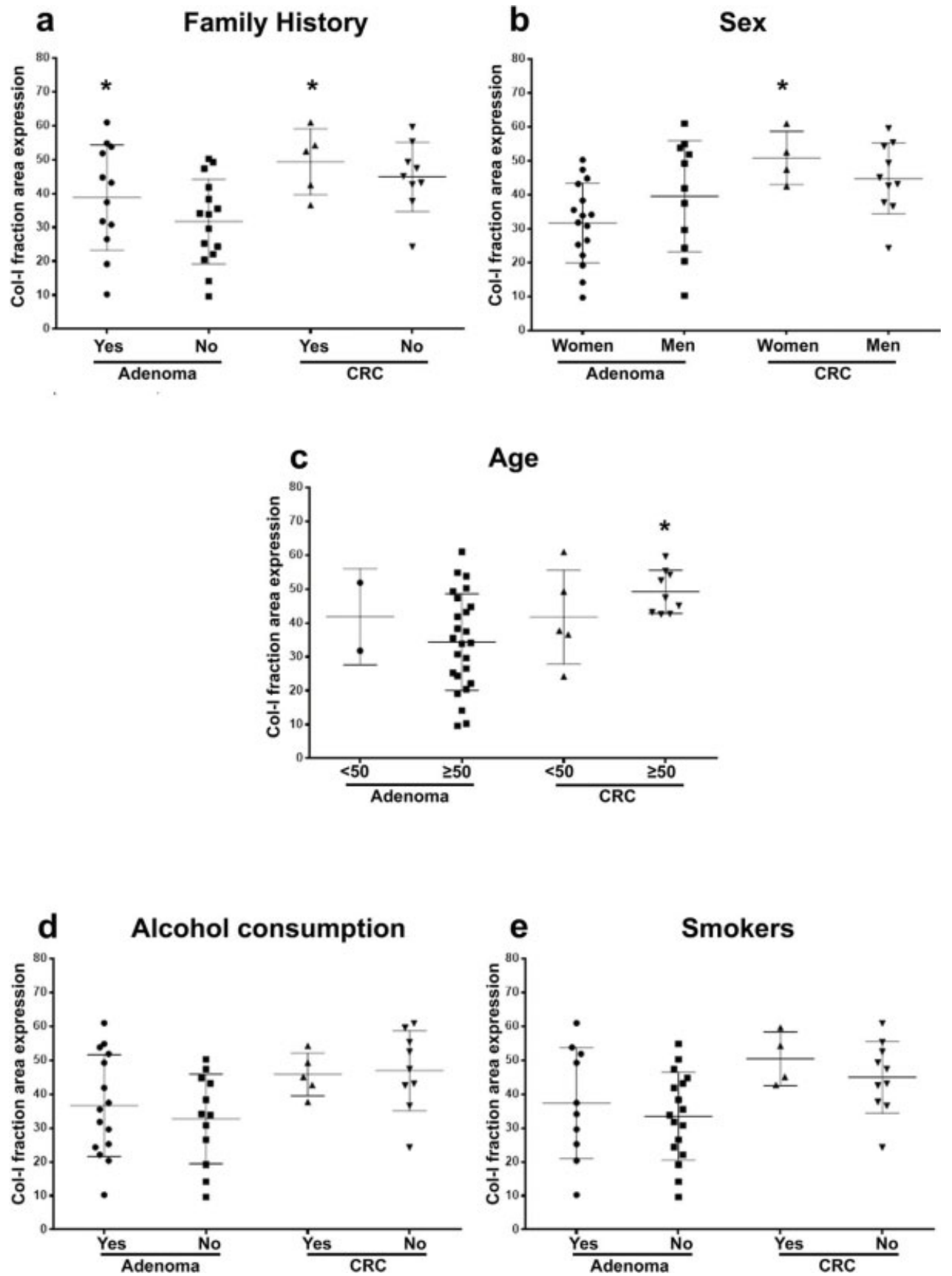

Fig. 2 Analysis of the correlations of the clinical factors of the patients and Col-l expression resulted in positive data regarding gender, age, and family history in cases of adenomas and colorectal cancer (CRC). This suggests that higher levels of expression are present in patients with adenoma or CRC and positive family history (A; $p=0.0325$. Median/standard error of the mean (SEM): 40.31/4.493; 33.78/3.224; 52.50/4.341; 45.05/3.406), female with CRC (B; $p=0.0251$. Median/SEM: 32.80/2.937; 41.88/4.964; 49.94/3.923; 44.09/3.310), and age $\geq 50$ years with CRC (C; $p=0.0446$. Median/SEM: 41.85/10.04; 34.09/2.850; 37.68/6.216; 47.37/2.125). A trend towards higher levels of immunostaining was observed among alcoholic patients with adenoma (D; $p=0.0761$. Median/SEM: 35.50/3.883; 33.94/3.805; 45.05/2.823; 47.37/3.930) and smokers with adenoma or CRC ( $E ; p=0.0572$. Mean/SEM: 35.75/5.186; 33.78/3.131; 49.65/3.937; 45.25/3.342). Two-way analysis of variance (ANOVA) and Kruskal-Wallis test.

between adenoma and CRC lesions, an important phenomenon of connective tissue accumulation caused by neoplastic processes together with host response. In this context, we could affirm that our results were capable not only to significantly demonstrate the increase in fibrous component in CRC cases, but also to establish positive correlations with the clinical data.

\section{Conclusion}

Col-I expression was found to be increased in CRC lesions compared to adenomas, benign stage, and cancer precursor, suggesting that the development of the most aggressive phenotype in the colorectal region is accompanied by important changes in the biochemical and physical aspects 
of the ECM. The clinicopathological positive correlations represented a relevant finding. These results may encourage more studies with the aim of finding biomarkers of CRC progression. Moreover, they demonstrate how comprehensive the clinical analysis of the patient may need to be in order for physicians to provide a suitable follow-up.

\section{Funding}

This work was supported by grants from Conselho Nacional de Desenvolvimento Científico e Tecnológico (CNPq) under process number: 479694 2013-3, and by Fundação de Amparo à Pesquisa e Inovação do Espírito Santo (FAPES) under process number: 67659870 006/2014.

\section{Conflict of Interests}

The authors have no conflict of interests to declare.

\section{Acknowledgments}

The Multi-user Histotechnique Laboratory of Universidade Federal do Espírito Santo played an important role in the histopathological experiments.

\section{References}

1 Siegel RL, Miller KD, Jemal A. Cancer statistics, 2018. CA Cancer J Clin 2018;68(01):7-30

2 Lurje G, Zhang W, Lenz HJ. Molecular prognostic markers in locally advanced colon cancer. Clin Colorectal Cancer 2007;6 (10):683-690

3 Lucas C, Barnich N, Nguyen HTT. Microbiota, inflammation and colorectal cancer. Int J Mol Sci 2017;18(06):1310

4 Mármol I, Sánchez-de-Diego C, Pradilla Dieste A, Cerrada E, Rodriguez Yoldi MJ. Colorectal carcinoma: a general overview and future perspectives in colorectal cancer. Int J Mol Sci 2017;18 (01):197

5 Norollahi SE, Hamidianb SMT, Kohparc ZK, et al. The fluctuation of APC gene in WNT signaling with adenine deletion of adenomatous polyposis coli, is associated in colorectal cancer. J Coloproctol (Rio J) 2020;40(02):135-142

6 Zhang Z, Wang Y, Zhang J, Zhong J, Yang R. COL1A1 promotes metastasis in colorectal cancer by regulating the WNT/PCP pathway. Mol Med Rep 2018;17(04):5037-5042

7 Kehlet SN, Sanz-Pamplona R, Brix S, Leeming DJ, Karsdal MA, Moreno V. Excessive collagen turnover products are released during colorectal cancer progression and elevated in serum from metastatic colorectal cancer patients. Sci Rep 2016;6:30599

8 Nyström H, Naredi P, Berglund A, Palmqvist R, Tavelin B, Sund M. Liver-metastatic potential of colorectal cancer is related to the stromal composition of the tumour. Anticancer Res 2012;32(12): 5183-5191

9 Ueno H, Kanemitsu Y, Sekine S, et al. A Multicenter Study of the Prognostic Value of Desmoplastic Reaction Categorization in Stage II Colorectal Cancer. Am J Surg Pathol 2019;43(08):1015-1022

10 Yue X, Nguyen TD, Zellmer V, Zhang S, Zorlutuna P. Stromal cellladen 3D hydrogel microwell arrays as tumor microenvironment model for studying stiffness dependent stromal cell-cancer interactions. Biomaterials 2018;170:37-48

11 Thiery JP, Acloque H, Huang RY, Nieto MA. Epithelial-mesenchymal transitions in development and disease. Cell 2009;139(05): 871-890

12 Huang C, Liu H, Gong X, et al. Analysis of different components in the peritumoral tissue microenvironment of colorectal cancer: A potential prospect in tumorigenesis. Mol Med Rep 2016;14(03): 2555-2565

13 van Huizen NA, Coebergh van den Braak RRJ, Doukas M, Dekker LJM, IJzermans JNM, Luider TM. Up-regulation of collagen proteins in colorectal liver metastasis compared with normal liver tissue. J Biol Chem 2019;294(01):281-289

14 Kirkland SC. Type I collagen inhibits differentiation and promotes a stem cell-like phenotype in human colorectal carcinoma cells. Br J Cancer 2009;101(02):320-326

15 Zou X, Feng B, Dong T, et al. Up-regulation of type I collagen during tumorigenesis of colorectal cancer revealed by quantitative proteomic analysis. J Proteomics 2013;94:473-485

16 Alves IS, Coser PH, Loureiro GJ, et al. Fibrosis and Mast Cells in Colorectal Lesions: Significance in Adenoma-Colorectal Cancer Sequence and Association with Diet. J Gastrointest Cancer 2016; 47(03):278-286

17 Burnett-Hartman AN, Passarelli MN, Adams SV, et al. Differences in epidemiologic risk factors for colorectal adenomas and serrated polyps by lesion severity and anatomical site. Am J Epidemiol 2013;177(07):625-637

18 Tan J, Chen YX. Dietary and lifestyle factors associated with colorectal cancer risk and interactions with microbiota: fiber red or processed meat and alcoholic drinks. Gastrointest Tumors 2016;3(01):17-24

19 Cox TR, Erler JT. Metastasis Molecular Pathways: Connecting Fibrosis and Solid Tumour Molecular Pathways: Connecting Fibrosis and Solid Tumour Metastasis Staff Planners' Disclosures Learning Objectives. Clin Cancer Res 2014;20:3637-3643

20 Nebuloni M, Albarello L, Andolfo A, et al. Insight on colorectal carcinoma infiltration by studying perilesional extracellular matrix. Sci Rep 2016;6:22522

21 Conti J, Thomas G. The role of tumour stroma in colorectal cancer invasion and metastasis. Cancers (Basel) 2011;3(02):2160-2168

22 Silva EMR, Freitas VM, Bautz WG, de Barros LAP, da Gama de Souza LN. Immunohistochemical Study of Laminin-332 $\gamma 2$ Chain and MMP-9 in High Risk of Malignant Transformation Oral Lesions and OSCC. J Oral Maxillofac Res 2018;9(01):e3 